\title{
openheart Iron deficiency in heart failure with preserved ejection fraction: a systematic review and meta-analysis
}

\author{
Anna L Beale, ${ }^{1,2}$ Josephine Lillian Warren, ${ }^{2}$ Nia Roberts, ${ }^{3}$ Philippe Meyer, ${ }^{4}$ \\ Nick P Townsend, ${ }^{5}$ David Kaye ${ }^{1,2}$
}

\begin{abstract}
- Additional material is published online only. To view please visit the journal online (http://dx.doi.org/10.1136/ openhrt-2019-001012).
\end{abstract}

To cite: Beale AL, Warren JL, Roberts N, et al. Iron deficiency in heart failure with preserved ejection fraction: a systematic review and meta-analysis. Open Heart 2019;6:e001012.

doi:10.1136/

openhrt-2019-001012

Received 14 January 2019 Revised 14 February 2019 Accepted 4 March 2019

\section{Check for updates}

(C) Author(s) (or their employer(s)) 2019. Re-use permitted under CC BY-NC. No commercial re-use. See rights and permissions. Published by BMJ.

${ }^{1}$ Heart Failure Research Group, Baker IDI Heart and Diabetes Institute, Melbourne, Victoria, Australia

${ }^{2}$ Cardiology, Alfred Health, Melbourne, Victoria, Australia ${ }^{3}$ Knowledge Centre, University of Oxford Health Care Libraries, Oxford, UK

${ }^{4}$ Cardiology, University Hospital of Geneva, Geneva, Switzerland ${ }^{5}$ University of Bath, Bath, UK

Correspondence to Dr Anna L Beale; annalbeale@ gmail.com

\section{ABSTRACT}

Objective Iron deficiency (ID) has an established impact on outcomes in patients with heart failure with reduced ejection fraction; however, there is a lack of conclusive evidence in patients with heart failure with preserved ejection fraction (HFpEF). We sought to clarify the prevalence and impact of ID in patients with HFpEF. Methods A systematic search of Cohcrane, MEDLINE, EMBASE, Web of Science and CINAHL electronic databases was performed to identify relevant studies. Included studies defined HFpEF as heart failure with an ejection fraction $\geq 50 \%$. We used a random-effects meta-analysis to determine the composite prevalence of ID in patients with HFpEF across the included studies. Other outcomes were assessed with qualitative analysis due to a paucity of studies with comparable outcome measures.

Results The prevalence of ID in the included studies was $59 \%$ (95\% Cl $52 \%$ to $65 \%$ ). ID was associated with lower $\mathrm{VO}_{2}$ max in three of four studies reporting $\mathrm{VO}_{2}$ max as an outcome measure, lower functional status as determined by dyspnoea class or 6 min walk test in two of three studies, and worse health-related quality of life in both studies reporting on this outcome. Conversely, ID had no impact on death or hospitalisation in three of the four studies investigating this.

Conclusions ID is highly prevalent in patients with HFpEF and is associated with worse exercise capacity and functional outcomes, but not hospitalisation or mortality. Our study establishes that ID may play an important a role in HFpEF.

\section{INTRODUCTION}

Iron deficiency (ID) is a common comorbidity in hospital inpatients, affecting over half of elderly inpatients with a complex comorbidity burden ${ }^{1}$; and in the heart failure population, affecting approximately $50 \%$ of patients with heart failure with reduced or preserved ejection fraction. ${ }^{2}$ Heart failure may generate ID through multiple mechanisms. Initially, ID is thought to be due to a rise in the regulatory protein hepcidin, which prevents the release of iron from enterocytes and the reticuloendothelial system, and which may be increased in the setting of systemic inflammation. ${ }^{3}$ With more advanced

\section{Key questions}

What is already known about this subject?

- Iron deficiency adversely impacts functional status, heart failure hospitalisation and mortality in heart failure with reduced ejection fraction; however, its role in heart failure with preserved ejection fraction (HFpEF) is less clear.

What does this study add?

- This study synthesises the existing evidence on iron deficiency in HFpEF and highlights a high prevalence of iron deficiency in HFpEF, affecting functional status in this population.

How might this impact on clinical practice?

- The findings of this review inform the clinician of the importance of testing for iron deficiency in HFpEF and is of particular relevance in anticipation of the results of the FAIR-HFpEF study.

heart failure, however, intestinal dysfunction, with mucosal oedema, reduced gastric emptying and modified intestinal motility; reduced dietary consumption of iron-rich foods with anorexia; and increased blood loss due to anticoagulants and gastric ulceration may play more significant roles. ${ }^{34}$

The relationship between heart failure and ID is complex, however, as ID worsens heart failure prognosis and may be involved in myocardial remodelling. Studies in patients with heart failure with reduced ejection fraction (HFrEF) indicate significantly higher mortality, ${ }^{5}$ poorer exercise capacity as determined by $\mathrm{VO}_{2}$ max, ${ }^{6}$ lower endurance capacity and cardiac work productivity, ${ }^{7}$ and lower quality of life ${ }^{8}$ in ID compared with iron-replete patients. The mechanisms behind this are likely related to the role of iron in the metabolism of cells with high energy demands, such as cardiomyocytes and skeletal muscle ${ }^{9}$; due to its role in mitochondrial function, oxygen storage and metabolism. ${ }^{910}$ 


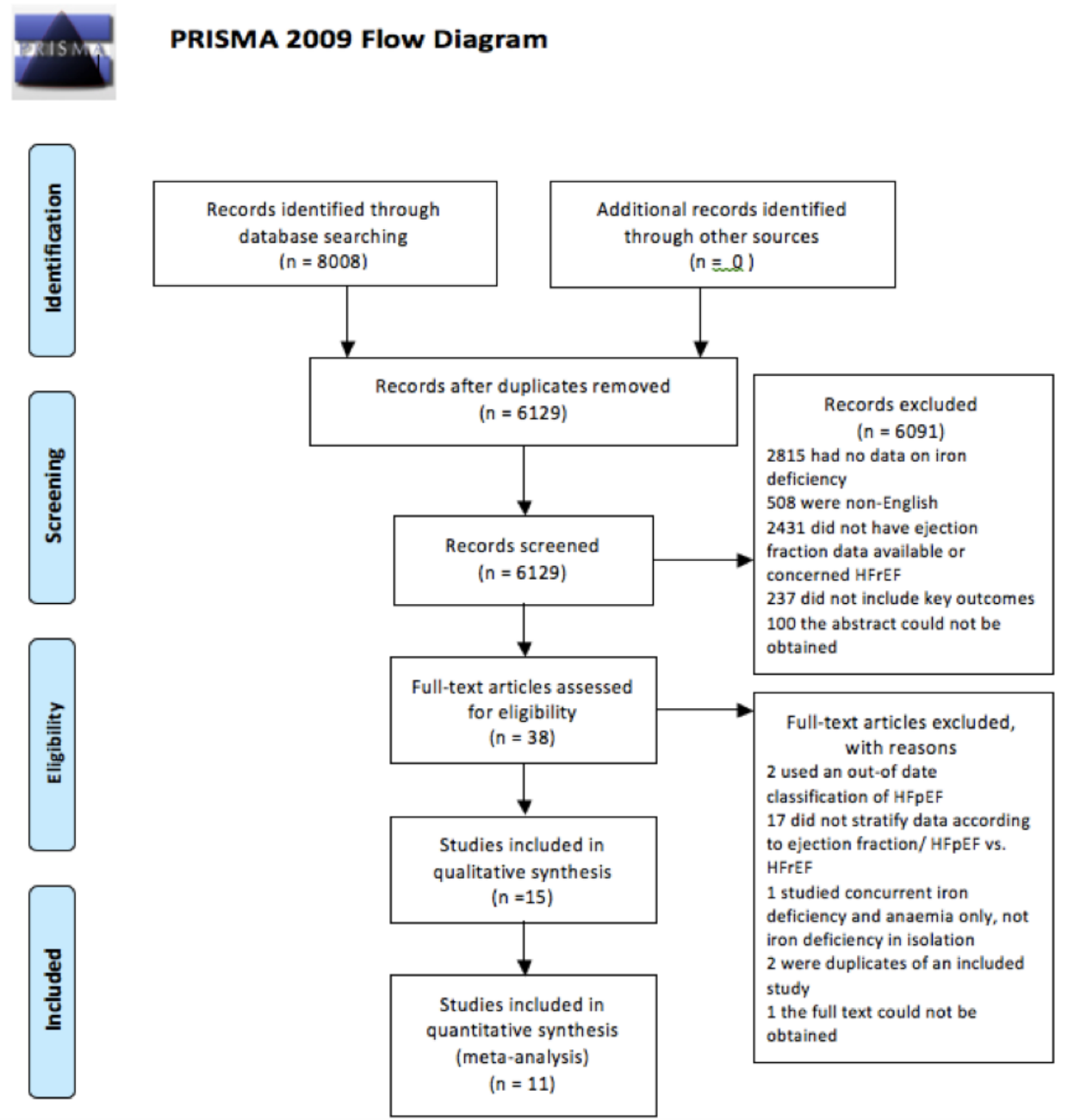

Figure 1 PRISMA flow chart.

Treatment of ID has largely centred around intravenous iron therapy in the HFrEF population due to the reduced absorption of oral iron in these patients and increased hepcidin levels, rendering oral therapy ineffective. ${ }^{3}$ Intravenous iron therapy increases quality of life, ${ }^{11}{ }^{12}$ regardless of whether patients are anaemic or not; improves functional outcomes such as dyspnoea score and $6 \mathrm{~min}$ walk test; and reduces both hospitalisation rates and heart failure-related mortality; all without an increase in adverse events. ${ }^{13}{ }^{14}$ However, the majority of studies and particularly meta-analyses have exclusively included patients with HFrEF. ${ }^{11} 1314$ This is significant, given the emerging epidemic of heart failure with preserved ejection fraction $(\mathrm{HFpEF})^{15}$; a population plagued by exercise intolerance and poor quality of life, and who have similar mortality rates to HFrEF. ${ }^{16-18}$

It is certainly plausible that ID may play a role in the pathogenesis and prognosis of HFpEF, and that treatment with intravenous iron therapy may therefore improve outcomes including functional status, hospitalisation and death. Studies to date investigating the role of iron deficiency in HFpEF have not reached a consensus on its prevalence and impact on heart failure outcomes. Therefore, the objective of this systematic review and meta-analysis is to estimate the prevalence of ID in patients with HFpEF. Furthermore, this review aims to detail the impact that ID has on functional outcomes, such as exercise tolerance and quality of life, along with hard clinical endpoints such as hospitalisation and mortality. This is the first review to our knowledge addressing these questions and plays an important role in outlining the significance of ID in HFpEF.

\section{METHODS \\ Protocol and registration}

Our review followed the Preferred Reporting Items for Systematic Reviews and Meta-Analyses (PRISMA) guidelines for systematic reviews. The supporting PRISMA checklist is available as online supplementary information. The PROSPERO registered protocol number is 42017069896.

\section{Database and search strategies}

We conducted a comprehensive literature search for papers using a predetermined search strategy, described in online supplemental materials. The search strategy was developed in collaboration between the lead author and 
medical librarian. We conducted the search in English in the following electronic databases: EMBASE, Cochrane Database of Systematic Reviews, Cochrane Central Register of Controlled Trials, Database of Abstracts of Reviews of Effect, Ovid MEDLINE Epub Ahead of Print, In-Process and Other Non-Indexed Citations, Ovid MEDLINE Daily and Ovid MEDLINE, CINAHL and Web Of Science Core Collection. Reference lists of key papers identified within the literature search were also reviewed.

\section{Inclusion criteria}

Included studies evaluated the prevalence and impact of ID in patients with HFpEF, and the inclusion criteria, along with criteria for the diagnosis of HFpEF and ID, are detailed in online supplemental materials.

\section{Study selection and data extraction}

Citations from search results were screened separately and data collected in duplicate by JLW and ALB, as further detailed in online supplemental materials.

\section{Quality assessment}

A quality assessment was conducted on all papers by ALB and JLW at the time of data extraction, as further detailed in online supplemental materials.

\section{Synthesis of results}

Meta analysis was performed for the prevalence of ID in HFpEF using the 'meta' package for R statistics using the inverse variance method. We used a random-effects meta-analysis as the studies were conducted in a range of settings and populations. Statistical heterogeneity was assessed using the $\mathrm{I}^{2}$ statistic. Meta analysis of prevalence was repeated for functional and absolute iron deficiency separately.

Due to the considerable heterogeneity of included studies with regard to their study design and outcome measures, including measurement of effect, meta-analysis was not possible for functional outcomes or hospitalisation and mortality outcomes according to ID in HFpEF. Instead, data were extracted into tables, categorised by outcome category and results described.

\section{RESULTS}

\section{Study selection}

The database search retrieved 8008 citations. After the removal of 1713 duplicates and 166 animal studies, there were 6129 citations that underwent title and abstract screening. Of this, 38 studies underwent full-text screening, and 15 met the inclusion criteria. The primary reason that studies were excluded at the time of full-text review was that data were not stratified according to ejection fraction, and therefore the cohort with HFpEF could not be assessed. The study selection process is further detailed in figure 1.

\section{Study characteristics}

Included studies were published between 2013 and 2017, reflecting our inclusion of those that met the 2012

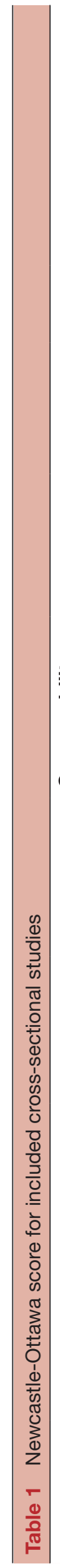

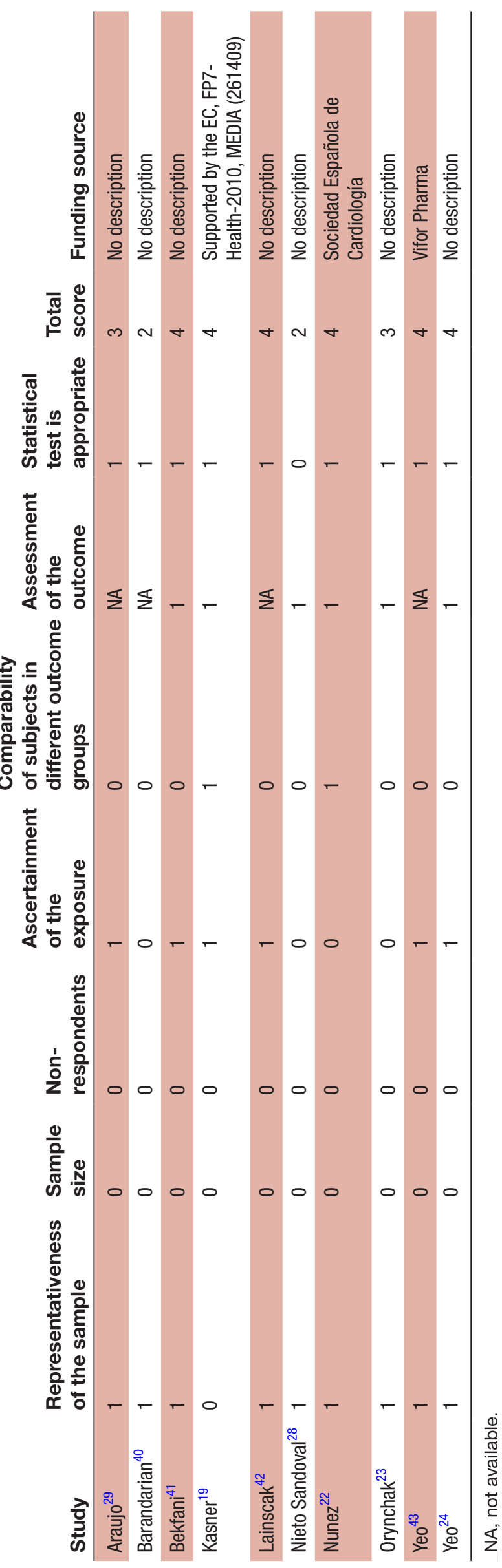




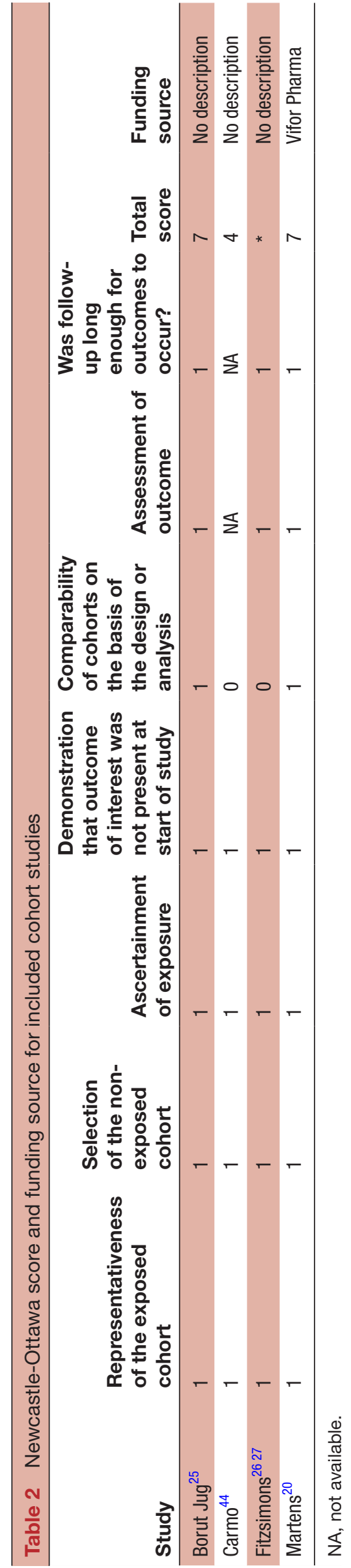

European Society of Cardiology (ESC) guidelines criteria for the diagnosis of HFpEF, with an $\mathrm{EF} \geq 50 \%$. The total number of patients with HFpEF from these 15 studies was 1877 . Studies reporting the percentage of women in their cohorts ranged from $42 \%$ to $69.8 \%$ women. In those reporting average age of participants, the average age ranged from $53 \pm 8$ to $79.8 \pm 8$ years.

\section{Quality assessment of included studies}

Tables 1 and 2 show the quality of the studies as evaluated using the Newcastle-Ottawa Scale. A summary of the quality assessment is detailed in online supplemental materials. Overall, the Grade quality of evidence was very low $(\otimes \mathrm{OOO})$, as a result of being based on a relatively small number of observational studies with substantial heterogeneity.

\section{Definition of iron deficiency}

The majority of studies used a definition of iron deficiency as a ferritin level $<100 \mu \mathrm{g} / \mathrm{L}$ or $100-300 \mu \mathrm{g} / \mathrm{L}$ with a transferrin saturation $<20 \%$; however, three studies (Nieto Sandoval et al, Nunez et al, Orynchak et al) did not explicitly outline how iron deficiency was defined.

\section{Prevalence of ID in HFpEF}

The pooled prevalence of ID in HFpEF is shown in figure 2. The pooled results of 11 studies suggested a prevalence of iron deficiency in HFpEF of $59 \%$ (95\% CI $52 \%-65 \%, \mathrm{I}^{2}=80 \% ; 1424$ participants). The prevalence of functional and absolute ID are represented in figures 3 and 4 , respectively. The prevalence of functional ID was $34 \%$ (95\% CI $18 \%$ to $54 \%, \mathrm{I}^{2}=96 \%, 832$ participants) and absolute ID $30 \%$ (95\% CI $17 \%$ to $46 \%, \mathrm{I}^{2}=93 \%, 678$ participants). There was considerable heterogeneity across all analyses, particularly in sub-analyses of functional and absolute ID. In the meta-analysis of overall prevalence of ID, removal of the study by Araujo et al significantly reduced the heterogeneity to $47 \%$ (prevalence $61 \%, 95 \%$ CI $57 \%$ to $65 \%$ ).

\section{Outcomes of ID in HFpEF}

A range of different outcome measures were employed across the included studies, as detailed in table 3 .

The most common outcome measure was oxygen consumption at peak exercise $\left(\mathrm{VO}_{2} \max \right)$, which was used in four studies. The $\mathrm{VO}_{2}$ max (and exercise time achieved) did not differ between ID and iron-replete groups in the study by Kasner et al $(17 \pm 1.5 \mathrm{~mL} / \mathrm{min} / \mathrm{kg}$ ID vs $18 \pm 3 \mathrm{~mL} / \mathrm{min} / \mathrm{kg}$ iron replete, $\mathrm{p}=0.93),{ }^{19}$ whereas it was significantly higher in iron-replete patients in the study by Martens et al $(16 \pm 5 \mathrm{~mL} / \mathrm{min} / \mathrm{kg}$ iron replete, $9 \pm 2 \mathrm{~mL} / \mathrm{min} / \mathrm{kg}$ ID, $\mathrm{p}<0.001) .{ }^{20}$ Two studies, by Bekfani et al and Nunez et al, found a significant positive correlation between indices of iron stores and $\mathrm{VO}_{2}$ max. Bekfani et al showed a positive correlation between ferritin and peak $\mathrm{VO}_{2}(\mathrm{r}=0.28, \mathrm{p}=0.03)^{21}$ along with a positive correlation between ferritin and exercise time $(\mathrm{r}=0.31, \mathrm{p}=0.01)$; and Nunez et al found positive correlations between both transferrin saturation $(\mathrm{r}=0.46, \mathrm{p}=0.003)$ and ferritin 


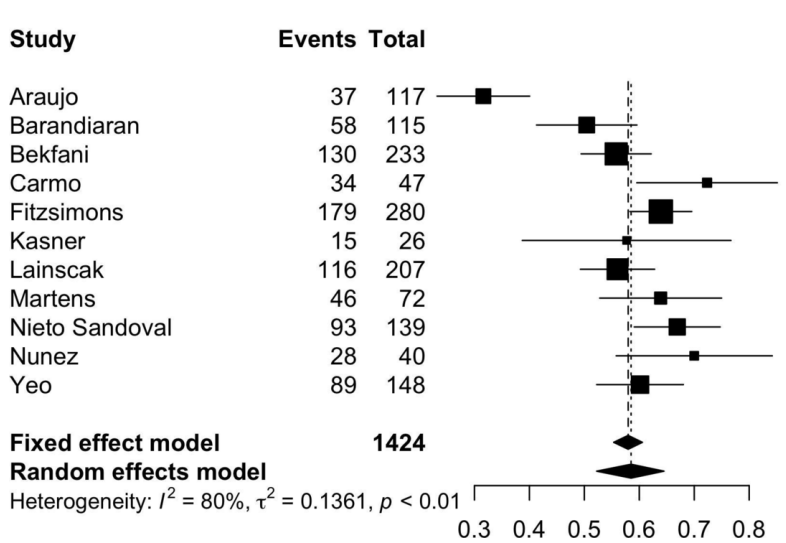

\begin{tabular}{|c|c|c|c|}
\hline Proportion & $95 \%-\mathrm{Cl}$ & $\begin{array}{l}\text { Weight } \\
\text { (fixed) }\end{array}$ & $\begin{array}{l}\text { Weight } \\
\text { (random) }\end{array}$ \\
\hline 0.32 & {$[0.23 ; 0.40]$} & $7.6 \%$ & $9.5 \%$ \\
\hline 0.50 & {$[0.41 ; 0.60]$} & $8.6 \%$ & $9.8 \%$ \\
\hline 0.56 & {$[0.49 ; 0.62]$} & $17.2 \%$ & $10.9 \%$ \\
\hline 0.72 & {$[0.60 ; 0.85]$} & $2.8 \%$ & $6.9 \%$ \\
\hline 0.64 & {$[0.58 ; 0.70]$} & $19.3 \%$ & $11.1 \%$ \\
\hline 0.58 & {$[0.39 ; 0.77]$} & $1.9 \%$ & $5.7 \%$ \\
\hline 0.56 & {$[0.49 ; 0.63]$} & $15.3 \%$ & $10.8 \%$ \\
\hline 0.64 & {$[0.53 ; 0.75]$} & $5.0 \%$ & $8.5 \%$ \\
\hline 0.67 & {$[0.59 ; 0.75]$} & $9.2 \%$ & $9.9 \%$ \\
\hline 0.70 & {$[0.56 ; 0.84]$} & $2.5 \%$ & $6.6 \%$ \\
\hline 0.60 & {$[0.52 ; 0.68]$} & $10.6 \%$ & $10.2 \%$ \\
\hline 0.58 & {$[0.55 ; 0.61]$} & $100.0 \%$ & \\
\hline 0.59 & {$[0.52 ; 0.65]$} & -- & $100.0 \%$ \\
\hline
\end{tabular}

Figure 2 Pooled prevalence of iron deficiency in patients with HFpEF.

$(\mathrm{r}=0.30, \mathrm{p}=0.048)$ with $\log \mathrm{VO}_{2}$ max, ${ }^{22}$ adjusting for gender, heart rate, NT-proBNP, glomerular filtration rate, $\mathrm{E} / \mathrm{e}^{\prime}$, haemoglobin and tricuspid annular plane systolic excursion.

Another measure of exercise tolerance and symptoms employed was the New York Heart Association (NYHA) functional class. Orynchak et al found that worsening NYHA class was associated with lower serum iron, ferritin and transferrin saturation, regardless of anaemia status. ${ }^{23}$ Conversely, Yeo et al found that patients with functional ID had no difference in NYHA class compared with iron-replete patients $(1.85$ vs $2, \mathrm{p}=0.16){ }^{24}$ The $6 \mathrm{~min}$ walk test (6MWT) was assessed in one study, Bekfani et $a$, finding a shorter distance covered in ID patients $(416 \pm 125 \mathrm{~m}$ iron replete vs $367 \pm 138 \mathrm{~m} \mathrm{ID}, \mathrm{p}=0.05)$ and that ferritin correlated positively with distance walked $(\mathrm{r}=0.24, \mathrm{p}=0.01) .^{21}$

Two studies assessed the impact of iron deficiency on patient-reported quality of life. Bekfani et al used the EQ-5D questionnaire and found a significantly lower quality of life in ID patients (19 062 \pm 4704 iron replete vs $16373 \pm 5304 \mathrm{ID}, \mathrm{p}<0.05) .{ }^{21}$ Similarly, Yeo et al used the Minnesota Living With Heart Failure Questionnaire (MLWHFQ), finding a lower score in ID patients (ID 28 vs iron replete $36, \mathrm{p}<0.05$ ), indicative of poorer quality of life. ${ }^{24}$

The composite outcomes of death and hospitalisation were frequently used. Martens et al assessed all-cause mortality and hospitalisation, with significantly higher rates of this composite outcome in ID patients (OR not detailed, $\mathrm{p}=0.001) \cdot{ }^{20}$ However, Borut Jug et al also analysed differences in composite death and rehospitalisation, which was not significantly different between ID and iron-replete patients (OR 1.88, 95\% CI 0.917 to 3.861, $\mathrm{p}=0.085$ for ID patients) ${ }^{25}$ Fitzsimons et al investigated the outcome of death between ID and iron-replete patients, finding no significant difference (HR 0.98, 95\% CI 0.53 to $1.81, \mathrm{p}=0.95$ for ID patients).$^{26}{ }^{27}$ In fact, Nieto Sandoval et al reported a positive correlation between ferritin and mortality; however, statistics were not quoted. ${ }^{28}$

Kasner et al investigated differences in NT-proBNP between iron-replete and ID patients, finding no difference $(192 \pm 199$ ID vs iron replete $169 \pm 109, p=0.095) .{ }^{19}$

\section{DISCUSSION}

In this systematic review, 15 studies with 1877 patients with HFpEF in total were included. We performed a meta-analysis of the prevalence of ID in HFpEF including 1424 patients, highlighting a high prevalence of $59 \%$ in this population. In the qualitative analysis of the included studies in this systematic review, the majority demonstrated an association between ID and poorer functional capacity as determined by $\mathrm{VO}_{2}$ max, NYHA class, 6MWT and quality of life. Conversely, three of the four studies assessing the impact of ID on death and rehospitalisation in HFpEF failed to find an association.

The prevalence of ID in HFpEF of 59\% is higher than the prevalence of ID in patients with heart failure overall in an international pooled analysis, at $50 \%,{ }^{2}$ suggesting that ID is even more common in patients with HFpEF than patients with HFrEF. There was substantial heterogeneity in the estimate of ID prevalence, with an $\mathrm{I}^{2}$ of $80 \%$; however, this improved significantly to $47 \%$ after
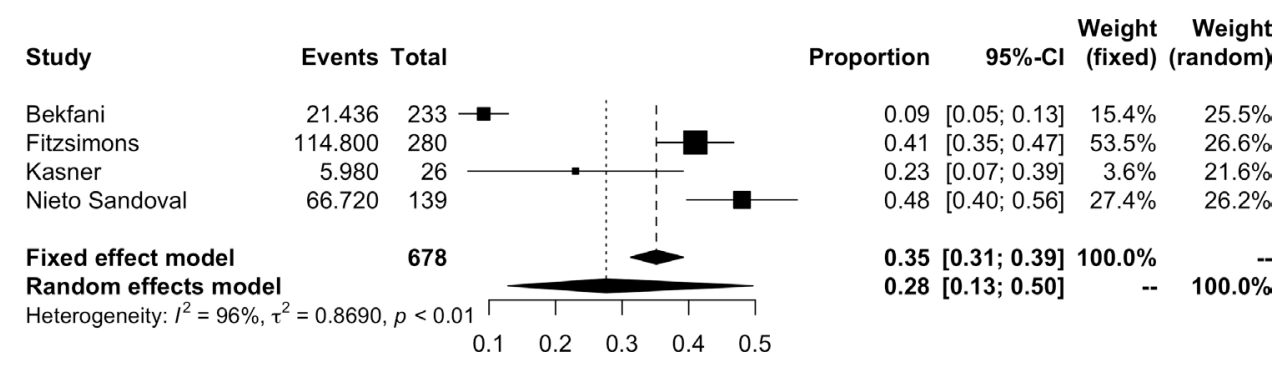

Figure 3 Meta-analysis of functional iron deficiency prevalence. 


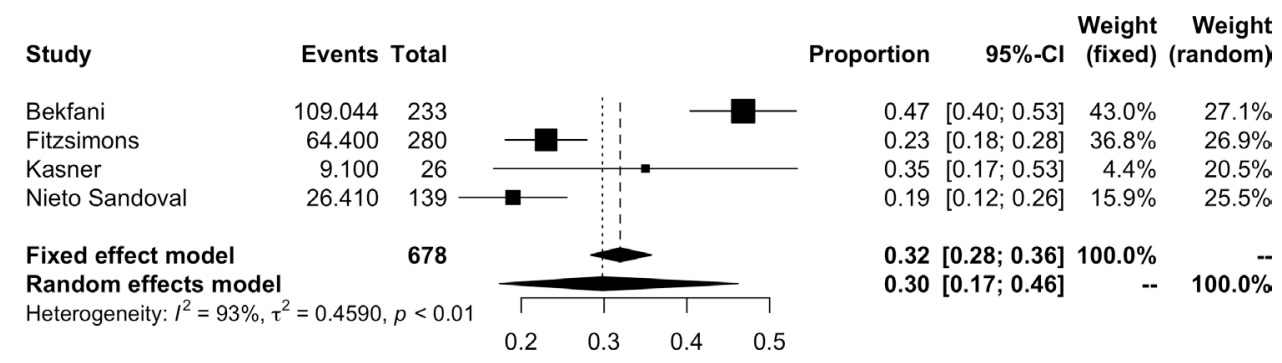

Figure 4 Meta-analysis of absolute iron deficiency prevalence.

removal of a single study ${ }^{29}$ that reported a much lower prevalence than the remaining 10 studies. This suggests that we can be reasonably confident that the prevalence of ID in HFpEF is approximately $60 \%$. The high prevalence of ID underscores the importance of performing iron studies in patients with HFpEF and HFrEF alike.

ID had a deleterious impact on exercise tolerance and functional capacity in the majority of studies included in our qualitative review. Three out of four studies found a relationship between ID and worse $\mathrm{VO}_{2} \max ,{ }^{20}$ with similar findings of reduced exercise time with ID. $\mathrm{VO}_{2}$ max is central to exercise tolerance and is markedly reduced in patients with HFpEF for whom impaired exercise capacity is a cardinal feature. ${ }^{30}$ There are numerous sequences in the oxygen consumption pathway, which is a complex interaction of respiratory, cardiovascular, haematological and skeletal muscle components. ${ }^{30}$ ID can affect multiple aspects of this pathway, including reducing oxygen storage and oxygen-carrying capacity, and causing mitochondrial dysfunction in both heart and skeletal muscle, resulting in reduced energetic efficiency and anaerobic metabolism. ${ }^{10}$

Furthermore, ID may have direct impacts on myocardial remodelling. Animal studies have indicated that severe ID can result in significant cardiac remodelling with left ventricular hypertrophy, fibrosis and diastolic dysfunction. ${ }^{31}$ This is yet to be established in patients with HFpEF; however, there is evidence in the HFrEF cohort, in a study of cardiac resynchronisation therapy (CRT). Patients with HFrEF were followed up for $38 \pm 22$ months following CRT implantation, and $56 \%$ of patients who were iron deficient at the time of initiation of CRT therapy experienced significantly less improvement in left ventricular end-diastolic diameter and less of an increase in left ventricular ejection fraction than those who were iron replete. In addition to these differences in remodelling, ID predicted more heart failure admissions and higher all-cause mortality, along with less symptomatic improvement with CRT. ${ }^{32}$ This could suggest a role for ID in mediating myocardial remodelling.

This review also identified consistent reductions in quality of life in the two studies that included this as an outcome measure, using the EQ-5D ${ }^{21}$ and $\mathrm{MLWHFQ}^{24}$ questionnaires. A reduced quality of life in patients with HFpEF who are iron deficient could be due to the aforementioned association with reduced exercise tolerance, limiting patients' capacity to complete activities of daily living and engage in leisure activities. Furthermore, ID has strong associations with fatigue, which is a likely contributor to this finding. Indeed, the CONFIRM-HF study of intravenous iron treatment in patients with HFrEF found an improvement in fatigue score with the correction of ID with ferric carboxymaltose. ${ }^{33}$

In patients with HFrEF, ID is associated with significantly poorer survival ${ }^{34}$; however, clinical trials of intravenous ferric carboxymaltose therapy for ID have not demonstrated a reduction in mortality in patients with HFrEF. ${ }^{33}$ While the study by Martens et al demonstrated a significantly higher composite outcome of hospitalisation and mortality in ID patients with $\mathrm{HFpEF},{ }^{20}$ the remaining three studies investigating this relationship did not substantiate this; in fact, the study by Nieto Sandoval et al found that survival worsened with increasing ferritin. ${ }^{25} 2628$ This may suggest that ID plays a more important role in functional outcomes, rather than impacting hospitalisation and survival. Despite the aforementioned relationship between ID and survival in HFrEF, this parallels what has been found in trials of intravenous ferric carboxymaltose in HFrEF.

Exercise intolerance is central to HFpEF, highlighted by the improved diagnostic acumen of stress echocardiography and exercise invasive haemodynamics for HFpEF relative to resting investigations. ${ }^{36}{ }^{37}$ Exercise intolerance often precedes the development of overt HFpEF and episodes of decompensated heart failure, and therefore the greatest potential impact of ID may be in those patients with earlier stages of HFpEF, worsening symptoms and affecting functional outcomes rather than hospitalisation for heart failure or mortality in the later stages of the disease. Interestingly, patients with HFpEF are more likely to die of non-cardiac causes than patients with HFrEF, ${ }^{38}$ which could blunt the effect that ID has on mortality in HFpEF.

This review establishes a clear role for ID in worsening exercise tolerance, functional outcomes and quality of life in patients with HFpEF. It carries implications for the potential therapeutic benefit of intravenous iron treatment in patients with HFpEF, which could foreseeably significantly improve HFpEF patients' quality of life and function. This paves the way for the FAIR-HFpEF study, which is currently recruiting (NCT03074591).$^{39}$ Based on the results of this systematic review, it is less clear whether intravenous ferric carboxymaltose will have an impact on survival and hospitalisation for heart failure; however, 
Heart failure and cardiomyopathies

Table 3 Prevalence and outcomes of iron deficiency (summary of findings table)

\begin{tabular}{|c|c|c|c|c|c|c|c|c|c|}
\hline \multirow[b]{2}{*}{ Study } & \multirow{2}{*}{$\begin{array}{l}\text { Sample } \\
\text { size } \\
\text { (HFpEF) }\end{array}$} & \multirow{2}{*}{$\begin{array}{l}\% \\
\text { women }\end{array}$} & \multirow{2}{*}{$\begin{array}{l}\text { Ejection } \\
\text { fraction } \\
\text { cut-off for } \\
\text { HFpEF }\end{array}$} & \multirow{2}{*}{$\begin{array}{l}\text { Average age } \\
\text { (years) }\end{array}$} & \multicolumn{3}{|c|}{ Prevalence of iron deficiency } & \multirow{2}{*}{$\begin{array}{l}\text { Outcome } \\
\text { measures }\end{array}$} & \multirow[b]{2}{*}{ Outcome } \\
\hline & & & & & Total & Absolute & Functional & & \\
\hline Araujo, $2015^{29}$ & 117 & 69.8 & $\geq 50 \%$ & $74.95 \pm 11.8$ & $31.4 \%$ & - & - & Nil (prevalence only) & NA \\
\hline $\begin{array}{l}\text { Barandiaran, } \\
2017^{40}\end{array}$ & 115 & 67.8 & $\geq 50 \%$ & - & $50 \%$ & - & - & Nil (prevalence only) & NA \\
\hline Bekfani, $2015^{41}$ & 233 & - & $\geq 50 \%$ & $71 \pm 9$ & $56 \%$ & $46.8 \%$ & $9.2 \%$ & $\begin{array}{l}\text { Peak } \mathrm{VO}_{2} \\
\text { Exercise time } \\
6 \mathrm{MWT} \\
\text { EQ-5D questionnaire }\end{array}$ & $\begin{array}{l}\text { Ferritin positively correlated with } \\
\text { peak V }{ }_{2}, r=0.28, p=0.03 \\
\text { Exercise time negatively correlated } \\
\text { with ferritin } r=0.31, p=0.01 \\
416 \pm 125 \mathrm{~m} \mathrm{IR}, 367 \pm 138 \mathrm{~m} \mathrm{ID} \text {, } \\
p=0.05 \\
\text { Ferritin correlated positively with } \\
\text { distance walked } r=0.24, p=0.01 \\
19062 \pm 4704 \mathrm{IR}, 16373 \pm 5304 \mathrm{ID} \text {, } \\
p<0.05\end{array}$ \\
\hline Borut Jug, $2016^{25}$ & 220 & - & Not described & - & - & - & - & $\begin{array}{l}\text { Death or } \\
\text { hospitalisation } \\
\text { (composite) }\end{array}$ & $\begin{array}{l}\text { OR } 1.88 \text { ( } 0.917-3.861), p=0.085 \text { for } \\
\text { iron-deficient patients } \\
\text { Adjusted for age, gender, NYHA } \\
\text { class, ischaemic aetiology, } \\
\text { natriuretic peptides, renal function, } \\
\text { anaemia }\end{array}$ \\
\hline Carmo, $2014^{44}$ & 47 & - & Not described & $78.9 \pm 9.2$ & $72.3 \%$ & - & - & Nil (prevalence only) & NA \\
\hline $\begin{array}{l}\text { Fitzsimons }{ }^{\star} \\
2015 / 2016^{2627}\end{array}$ & 280 & $45 \%$ & $\geq 50 \%$ & 73.8 & $64 \%$ & $23 \%$ & $41 \%$ & Death & $\begin{array}{l}\text { HR } 0.98(0.53-1.81), p=0.95 \text { for } \\
\text { iron-deficient patients }\end{array}$ \\
\hline Kasner, $2013^{19}$ & 26 & $42 \%$ & Not described & $55 \pm 8.5$ & $58 \%$ & $35 \%$ & $23 \%$ & $\begin{array}{l}\text { NT-proBNP levels } \\
(\mathrm{pg} / \mathrm{mL}) \\
\mathrm{VO}_{2}(\mathrm{~mL} / \mathrm{min} / \mathrm{kg}) \\
\text { Exercise } \\
\text { performance }(\mathrm{W})\end{array}$ & $\begin{array}{l}\text { NT-proBNP } 192 \pm 199 \text { ID vs } \\
169 \pm 109, p=0.095 \\
17 \pm 1.5 \text { ID vs } 18 \pm 3 \text { IR, } p=0.93 \\
102 \pm 25 \text { ID vs } 121 \pm 50 \text { IR, } p=0.49 \\
\text { Analyses were not adjusted but } \\
\text { patients had similar baseline } \\
\text { characteristics }\end{array}$ \\
\hline Lainscak, $2015^{42}$ & 207 & $42 \%$ & $\geq 50 \%$ & $71 \pm 12$ & $56 \%$ & - & - & $\begin{array}{l}\text { Nil (prevalence only } \\
\text { in HFpEF) }\end{array}$ & NA \\
\hline Martens, $2017^{20}$ & 72 & - & $\geq 50 \%$ & - & $64 \%$ & - & - & $\begin{array}{l}\mathrm{VO}_{2}(\mathrm{~mL} / \mathrm{min} / \mathrm{kg}) \\
\text { All-cause mortality } \\
\text { and hospitalisation }\end{array}$ & $\begin{array}{l}16 \pm 5 I R, 9 \pm 2 \text { ID, } p<0.001 \\
\text { Significantly higher in ID vs IR, } \\
p=0.001 \text {, adjusted for age, gender, } \\
\text { implantable cardioverter defibrillator } \\
\text { use, CRT use, ischaemic aetiology, } \\
\text { medication use and baseline LVEF }\end{array}$ \\
\hline $\begin{array}{l}\text { Nieto Sandoval, } \\
2017^{28}\end{array}$ & 139 & $65.3 \%$ & $\geq 50 \%$ & $79.8 \pm 8$ & $67 \%$ & $19 \%$ & $48 \%$ & Death & $\begin{array}{l}\text { Higher ferritin associated with } \\
\text { increased mortality in HFpEF } \\
\text { (statistics not quoted) }\end{array}$ \\
\hline Nunez, $2016^{22}$ & 40 & $55 \%$ & $\geq 50 \%$ & $74 \pm 5.5$ & $70 \%$ & - & - & $\mathrm{VO}_{2}$ & $\begin{array}{l}\text { Log V0, correlated with TSAT } \\
(r=0.46, p=0.003) \text { and ferritin } \\
\text { ( } r=0.30, p=0.048) \text { in HFpEF } \\
\text { Adjusted for gender, HR, NT-proBNP, } \\
\text { eGFR, E/e', Hb, TAPSE }\end{array}$ \\
\hline Orynchak, $2014^{23}$ & 79 & $65 \%$ & $\geq 50 \%$ & $53 \pm 8$ & - & - & - & NYHA class & $\begin{array}{l}\text { NYHA class II/III associated with } \\
\text { lower serum iron, ferritin and } \\
\text { transferrin regardless of anaemia } \\
\text { status }\end{array}$ \\
\hline Yeo, $2014^{43}$ & 154 & - & $\geq 50 \%$ & - & - & - & $61 \%$ & $\begin{array}{l}\text { Nil (prevalence only } \\
\text { for HFpEF) }\end{array}$ & NA \\
\hline Yeo, $2014 \dagger^{24}$ & 148 & - & $\geq 50 \%$ & - & $60.1 \%$ & - & - & $\begin{array}{l}\text { MLHFQ } \\
\text { NYHA functional } \\
\text { class }\end{array}$ & $\begin{array}{l}\text { Patients with FID had worse MLHFQ } \\
\text { compared with IR ( } 28 \text { vs } 36, p<0.05 \text { ) } \\
\text { Patients with FID had no difference } \\
\text { in NYHA class compared with IR } \\
(1.85 \text { vs } 2, p=0.16)\end{array}$ \\
\hline
\end{tabular}

*Fitzsimons et al had two papers reporting on the same cohort, therefore information on this cohort was gathered from the two publications and reported as the same population in our summary of findings table.

†Yeo et al did not use a standard definition of iron deficiency: they defined iron deficiency as transferrin saturation <20\%, without any criteria for ferritin.

CRT, cardiac resynchronisation therapy; FID, functional iron deficiency; HFpEF, heart failure with preserved ejection fraction; ID, iron deficient; IR, iron replete; LVEF,

left ventricular ejection fraction; MLHFQ, Minnesota Living with Heart Failure Questionnaire; 6MWT, 6 min walk test; NA, not available; NYHA, New York Heart

Association; TAPSE, tricuspid annular plane systolic excursion; TSAT, transferrin saturation. 
functional improvements may even be preferable in this predominantly elderly population.

The strength of our study is that it is the first to comprehensively synthesise the evidence surrounding the impact of ID on outcomes in patients with HFpEF. Furthermore, this systematic review and meta-analysis was performed in accordance with PRISMA recommendations, with independent reviewers for double data extraction and analysis. Therefore, the methodology of this study is sound and represents the best possible synthesis of the available literature.

There are several limitations of this study. Due to a lack of consistency in outcome variables reported by studies meeting our inclusion criteria, we were unable to perform a quantitative synthesis of any of the outcomes associated with ID in patients with HFpEF. A meta-analysis would have strengthened our conclusions regarding the impact of ID on exercise tolerance and functional outcomes. Part of the reason behind this variability in outcome measures was the small number of studies included in this systematic review, which was a result of the strict inclusion criteria to ensure that only patients with HFpEF according to the latest diagnostic criteria were included.

In addition, there was substantial heterogeneity in our findings, particularly in the meta-analysis of the prevalence of ID. This was further amplified when assessing the prevalence of functional and absolute ID separately, rendering these findings difficult to interpret. Sources of heterogeneity included considerable differences in the populations studied, along with different research methodologies. Furthermore, only four studies reported similar baseline characteristics or controlled for factors such as age, gender, ischaemic aetiology, natriuretic peptides, renal function and anaemia. ${ }^{19} 2022$ Heart failure itself causes ID, as do comorbid conditions such as chronic renal impairment, and therefore ID could be in part reflective of patients with a more severe HFpEF phenotype and concurrent comorbidities. It is important to interpret our findings with the consideration that some of the associations between ID and functional outcome may have been mediated by these confounders.

\section{CONCLUSION}

This systematic review analysed data from 1877 patients with HFpEF and found that ID is highly prevalent in this HFpEF population. Furthermore, the majority of studies included demonstrated a detrimental influence of ID on $\mathrm{VO}_{2}$, NYHA class, 6MWT and health-related quality of life. These findings are suggestive of an important role of ID in HFpEF, indicating that it has a similar impact to that in HFrEF.

Acknowledgements The authors would like to acknowledge the assistance of Kremlin Wickramasinghe and Peter Scarborough for their guidance in developing data extraction sheets for this manuscript.

Contributors All authors contributed to the conception of and execution of the research and the final manuscript preparation.
Funding The authors have not declared a specific grant for this research from any funding agency in the public, commercial or not-for-profit sectors.

Competing interests None declared.

Patient consent for publication Not required.

Ethics approval Not required

Provenance and peer review Not commissioned; externally peer reviewed.

Data sharing statement № additional data are available.

Open access This is an open access article distributed in accordance with the Creative Commons Attribution Non Commercial (CC BY-NC 4.0) license, which permits others to distribute, remix, adapt, build upon this work non-commercially, and license their derivative works on different terms, provided the original work is properly cited, appropriate credit is given, any changes made indicated, and the use is non-commercial. See: http://creativecommons.org/licenses/by-nc/4.0/.

\section{REFERENCES}

1. Fonseca C, Araújo M, Moniz P, et al. Prevalence and prognostic impact of anemia and iron deficiency in patients hospitalized in an internal medicine ward: the PRO-IRON study. Eur J Haematol 2017;99:505-13.

2. Klip IT, Comin-Colet J, Voors AA, et al. Iron deficiency in chronic heart failure: an international pooled analysis. Am Heart $J$ 2013;165:575-82.

3. McDonagh T, Macdougall IC. Iron therapy for the treatment of iron deficiency in chronic heart failure: intravenous or oral? Eur J Heart Fail 2015;17:248-62.

4. Wong CCY, Ng ACC, Kritharides L, et al. Iron deficiency in heart failure: Looking beyond anaemia. Heart, Lung and Circulation 2016;25:209-16.

5. Klip IJsbrandT, Comin-Colet J, Voors AA, et al. Iron deficiency in chronic heart failure: an international pooled analysis. Am Heart $J$ 2013;165:575-82.

6. Jankowska EA, Rozentryt P, Witkowska A, et al. Iron deficiency predicts impaired exercise capacity in patients with systolic chronic heart failure. J Card Fail 2011;17:899-906.

7. Haas JD, Brownlie T, Tt B. Iron deficiency and reduced work capacity: a critical review of the research to determine a causal relationship. The Journal of Nutrition 2001;131:676S-90. discussion 688S-690S.

8. Comín-Colet J, Enjuanes C, González G, et al. Iron deficiency is a key determinant of health-related quality of life in patients with chronic heart failure regardless of anaemia status. Eur J Heart Fail 2013;15:1164-72.

9. Jankowska EA, Rozentryt P, Witkowska A, et al. Iron deficiency: an ominous sign in patients with systolic chronic heart failure. Eur Heart J 2010;31:1872-80.

10. Cohen-Solal A, Damy T, Terbah M, et al. High prevalence of iron deficiency in patients with acute decompensated heart failure. Eur $J$ Heart Fail 2014;16:984-91.

11. Avni T, Leibovici L, Gafter-Gvili A. Iron supplementation for the treatment of chronic heart failure and iron deficiency: systematic review and meta-analysis. Eur J Heart Fail 2012;14:423-9.

12. Silverberg DS, laina A, Schwartz D, et al. Intravenous iron in heart failure: beyond targeting anemia. Curr Heart Fail Rep 2011;8:14-21.

13. Qian C, Wei B, Ding J, et al. The efficacy and safety of iron supplementation in patients with heart failure and iron deficiency: a systematic review and meta-analysis. Can J Cardiol 2016;32:151-9.

14. Kapoor M, Schleinitz MD, Gemignani A, et al. Outcomes of patients with chronic heart failure and iron deficiency treated with intravenous iron: a meta-analysis. Cardiovasc Hematol Disord Drug Targets 2013;13:35-44.

15. Oktay AA, Rich JD, Shah SJ. The emerging epidemic of heart failure with preserved ejection fraction. Curr Heart Fail Rep 2013;10:401-10.

16. Owan TE, Hodge DO, Herges RM, et al. Trends in prevalence and outcome of heart failure with preserved ejection fraction. $N$ Engl J Med 2006;355:251-9.

17. Bhatia RS, Tu JV, Lee DS, et al. Outcome of heart failure with preserved ejection fraction in a population-based study. $N$ Engl J Med 2006;355:260-9.

18. Bursi F, Weston SA, Redfield MM, et al. Systolic and diastolic heart failure in the community. JAMA 2006;296:2209-16.

19. Kasner M, Aleksandrov AS, Westermann D, et al. Functional iron deficiency and diastolic function in heart failure with preserved ejection fraction. International Journal of Cardiology 2013;168:4652-7. 
20. Martens P, Nijst P, Verbrugge FH, et al. Impact of iron deficiency on exercise capacity and outcome in heart failure with reduced, midrange and preserved ejection fraction. Acta Cardiologica 2017:1-9.

21. Bekfani T, Pellicori P, Ebner N, et al. Anker Sd and von Haehling $\mathrm{S}$. the prevalence of iron deficiency in patients with heart failure with preserved ejection fraction and its association with elevated pulmonary pressure, reduced exercise capacity and quality of life. Journal of Cardiac Failure 2015;1:S110-S111.

22. Núñez J, Domínguez E, Ramón JM, et al. Iron deficiency and functional capacity in patients with advanced heart failure with preserved ejection fraction. Int J Cardiol 2016;207:365-7.

23. Orynchak MA, Vakalyuk II, Chovganuyk OS, et al. Diagnostic value of iron deficiency state in hypertensives with chronic heart failure. J Am Soc Hypertens 2014;8:e95.

24. Yeo TJ, Daniel Yeo PS, Sim D, et al. PT081 functional iron deficiency in heart failure with preserved versus reduced ejection fraction. Global Heart 2014;9:e181.

25. Borut Jug B, Kosuta D, Omersa D, et al. Prognostic impact of iron deficiency in heart failure with preserved and reduced ejection fraction. Eur J Heart Fail 2016;18.

26. Fitzsimons S, Troughton R, Gamble GD, et al. Iron deficiency and anaemia do not predict mortality in heart failure with preserved ejection fraction (HF-PEF). Eur Heart J 2016;37:814

27. Fitzsimons S, Troughton R, Gamble GD, et al. High prevalence of iron deficiency in heart failure with preserved ejection fraction. Eur Heart J 2015;36:876-7.

28. Nieto Sandoval B, Jose Satue JA, Perez Martin A, et al. Iron stores and prognosis in a cohort of elderly patients with heart failure and preserved ejection fraction. Eur J Heart Fail 2017;19.

29. Araujo MB, Araujo I, Marques F, et al. Anemia and (combined) hematinic factors deficiency in heart failure. Eur Heart J 2015;36.

30. Houstis NE, Eisman AS, Pappagianopoulos PP, et al. Exercise intolerance in HFpEF: diagnosing and ranking its causes using personalized O2 pathway analysis. Circulation 2017:148-61.

31. Naito $\mathrm{Y}$, Tsujino T, Matsumoto M, et al. Adaptive response of the heart to long-term anemia induced by iron deficiency. Am J Physiol Heart Circ Physiol 2009;296:H585-93.

32. Martens $P$, Verbrugge F, Nijst $P$, et al. Impact of iron deficiency on response to and remodeling after cardiac resynchronization therapy. Am J Cardiol 2017;119:65-70.
33. Ponikowski P, van Veldhuisen DJ, Comin-Colet J, et al. Beneficial effects of long-term intravenous iron therapy with ferric carboxymaltose in patients with symptomatic heart failure and iron deficiency. Eur Heart J 2015;36:657-68.

34. Jankowska EA, Kasztura M, Sokolski M, et al. Iron deficiency defined as depleted iron stores accompanied by unmet cellular iron requirements identifies patients at the highest risk of death after an episode of acute heart failure. Eur Heart J 2014;35:2468-76.

35. Anker SD, Comin Colet J, Filippatos G, et al. Ferric carboxymaltose in patients with heart failure and iron deficiency. N Engl $J$ Med 2009;361:2436-48.

36. Obokata M, Kane GC, Reddy YN, et al. Role of diastolic stress testing in the evaluation for heart failure with preserved ejection fraction: a simultaneous invasive-echocardiographic study. Circulation 2017:135:825-38.

37. Borlaug BA, Nishimura RA, Sorajja P, et al. Exercise hemodynamics enhance diagnosis of early heart failure with preserved ejection fraction. Circ Heart Fail 2010;3:588-95.

38. Chan MMY, Lam CSP. How do patients with heart failure with preserved ejection fraction die? Eur J Heart Fail 2013;15:604-13.

39. Charite University B, Germany and Göttingen Uo. Effect of IV iron in patients with heart failure with preserved ejection fraction, 2017.

40. Barandiaran Aizpurua MA, Van Empel VPM. Personalized approach to heart failure with preserved ejection fraction (HFpEF), the Maastricht experience. Eur J Heart Fail 2017;19.

41. Bekfani TT, Pellicori P, Ebner N, et al. The prevalence of iron deficiency in patients with heart failure with preserved ejection fraction and its association with elevated pulmonary pressure, reduced exercise capacity and quality of life. Eur J Heart Fail 2015;17.

42. Lainscak M, Omersa D. Iron deficiency is highly prevalent in patients with heart failure with preserved ejection fraction. Eur $\mathrm{J}$ Heart Fail 2015;17.

43. Yeo TJ, Yeo PSD, Ching-Chiew Wong R, et al. Iron deficiency in a multi-ethnic Asian population with and without heart failure: prevalence, clinical correlates, functional significance and prognosis. Eur J Heart Fail 2014;16:1125-32.

44. Carmo J, Araujo I, Costa L, et al. Prevalence and prognostic impact of iron deficiency with or without anemia in heart failure with reduced and preserved ejection fraction. Eur J Heart Fail 2014;16. 